\title{
Can the "VUCA Meter" Augment the Traditional Project Risk Identification Process? A Case Study
}

\author{
Thordur Vikingur Fridgeirsson *, Helgi Thor Ingason* ${ }^{\mathbb{D}}$, Svana Helen Björnsdottir and Agnes Yr Gunnarsdottir \\ School of Engineering, Reykjavik University, Menntavegur 1, 101 Reykjavik, Iceland; svanahb@ru.is (S.H.B.); \\ agnesyg1996@gmail.com (A.Y.G.) \\ * Correspondence: thordurv@ru.is (T.V.F.); helgithor@ru.is (H.T.I.)
}

check for

updates

Citation: Fridgeirsson, T.V.; Ingason, H.T.; Björnsdottir, S.H.;

Gunnarsdottir, A.Y. Can the "VUCA

Meter" Augment the Traditional

Project Risk Identification Process? A

Case Study. Sustainability 2021, 13,

12769. https://doi.org/10.3390/

su132212769

Academic Editors: João Carlos de Oliveira Matias and Paolo Renna

Received: 21 October 2021

Accepted: 16 November 2021

Published: 18 November 2021

Publisher's Note: MDPI stays neutral with regard to jurisdictional claims in published maps and institutional affiliations.

Copyright: (c) 2021 by the authors. Licensee MDPI, Basel, Switzerland. This article is an open access article distributed under the terms and conditions of the Creative Commons Attribution (CC BY) license (https:/ / creativecommons.org/licenses/by/ $4.0 /)$.

\begin{abstract}
In this rapidly changing and fast-growing world, sustainability is an important paradigm. However, the constantly growing level of uncertainty leads to increased strain in decision making. This results in a growing need for a more effective and extensive approach for identifying project risk in particular events that are not easily detected but can have a severe impact, sometimes referred to as Black Swans or "fat tail" events. The VUCA meter is a normative approach to identify project risk by assessing in a structured way events that may be volatile, uncertain, complex, and ambiguous and might contribute to the project risk. In this study, the VUCA meter is benchmarked against a traditional risk identification process as recommended by PMI ${ }^{\circledR}$. Firstly, two workshops, each referring to the respective risk identification method, were conducted. Secondly, a Delphi survey was run to investigate if the VUCA meter would capture Black Swan risk events that are bypassed by the traditional risk identification approach. The results clearly indicate that the VUCA meter can be developed to be a significant addition to the conventional risk identification process for large projects that are at an early stage. The VUCA meter facilitates a discussion that gets people to think beyond the traditional framework for identifying project risk factors. As a consequence, "fat tail" events, that are not apprehended with the conventional technique, are captured by the VUCA meter.
\end{abstract}

Keywords: project management; risk management; risk identification; risk assessment; VUCA

\section{Introduction}

The Vadlaheiðargöng project is a $7.5 \mathrm{~km}$ mountain tunnel at the north coast of Iceland connecting the city of Akureyri with Fnjoskadalur. The initial business model for the tunnel project was presented in 2002. It was assumed that the construction and the operation of the tunnel would be a private-public enterprise with high feasibility and limited technical difficulties [1]. Road tolls would recover all costs within 20 years plus a macroeconomic gain of $8 \%$ [2]. When market financing folded due to the international finance crisis in 2008 , the arrangement was modified and the Icelandic government guaranteed a loan to make the construction possible. When the construction commenced, the Vadlaheiðargöng project soon hit some serious unforeseen problems. In the beginning of 2014, a major hot water leak, due to unexpected geothermal activity in the mountain, was detected making drilling impossible due to heat and steam. To be able to proceed, the contractor had to move the equipment to the other side of the mountain and continue drilling from there. Unfortunately, in April 2015, a major unexpected cold water leak was discovered on the new drilling site. The water completely floated the tunnel causing serious problems. A famous news clip from this period shows a TV reporter rowing a boat inside the tunnel to investigate the conditions. The tunnel was scheduled to be ready for traffic in 2016 (the initial plan assumed 2011). However, it was only operative in December 2018, more than two years later than planned [1]. The cost overrun in 2017 was estimated at $44 \%$. However, it should be noted that in the presented cost overrun number, the cost of finance was not included and the real total cost overrun is thus much higher [3]. In July 2019, it was noted 
that the income from the tolls was 35-40\% less than expected [4]. Moreover, the COVID-19 pandemic resulted in a major breach in traffic volume in 2020, as the Icelandic tourist industry collapsed and local people were encouraged to limit their mobility as much as possible. This brief overview of a recent extensive infrastructure project is an appropriate prelude to a paper on a new method for assessing project risk in the modern fast changing and turbulent environment that is also urging for sustainable solutions.

We published our study on the VUCA meter, "The VUCA'ility of Projects; A New Approach to Assess a Project Risk in a Complex World" in the beginning of 2021 [5]. The study introduced a risk identification tool to supplement the conventional approach for risk assessment, advocated by international project management associations such as PMI (Project Management Institute). The initial idea assumes that we live in a VUCA business world [6] where volatility, uncertainty, complexity, and ambiguity prevail. In this rapidly changing environment, the need for a comprehensive risk identification process has become more remarkable and more significant in any project preparation [7]. The conventional risk assessment model is based on evaluating risk events based on two variables, the likelihood of the occurrence and the impact the risk event would have if it occurred. These two values are then used to rank the possible risk events to determine the most significant ones [8]. However, studies, such as Ackermann et al. [9], mention that the conventional approach used to identify and assess risk is too narrow and might not detect a "wider set of risks". The short narrative on Vadlaheidargöng, earlier in this text, is descriptive for the "unknown unknowns" that a project planner can be confronted with. An international economic collapse, an unknown hot water vein, and an unknown cold water source effected the project lifecycle negatively. Furthermore, the COVID-19 pandemic almost wiped out the number of tourists visiting Iceland in 2020 reducing even further the expected tunnel traffic. It is questionable that the conventional approach would detect a low probability and high impact risk event such as the COVID-19 pandemic, political undercurrents caused by unconventional politicians such as president Trump, uncertainty in weather-related incidents due to climate changes, and so on. Furthermore, assessors and decision makers may have cognitive limitations to make judgments on probabilities, as was determined by the seminal work of Daniel Kahneman and Amos Tversky who published their findings in a series of papers in the early 1970s [10]. The central theme of their work is that people use simple mental strategies to cope with complex estimates and make judgments. This alone justifies further considerations of whether a traditional risk identification and assessment can be improved to ensure it covers possible risk factors in a more comprehensive way. Bent Flybjerg [11] has recommended the use of "reference class forecasting", a forecasting method based on empirical evidence, to bypass the biases of human judgments [11]. The problem of the limitations of traditional risk management is, e.g., well documented by the influential work of Nassim Taleb [12,13]. Low probability and high impact events are often referred to as "Black Swan" events and the fallacy of overlooking them is named the "ludic fallacy". The ludic fallacy states that decision makers might ignore small variations in the data that could have huge impact. This is also referred to as "fat tail risk", referring to the tails of the normal distribution-located several standard deviations from the mean [13]. Taleb [12] defines a Black Swan as an event meeting three criteria: (a) it is an outlier as it lies outside the realm of regular expectations, (b) it carries extreme impact, and (c) human nature makes us put together explanations for its occurrence afterwards, making it seem explainable and predictable.

In response to the need to seclude risk events, arguably overlooked by the conventional approach, we presented the VUCA meter, intended to complement the conventional risk identification and assessment. The meter is based on the VUCA concept explained briefly later in this text, which stands for volatility, uncertainty, complexity, and ambiguity. The VUCA meter endeavors to investigate the VUCA'ility of the project. An example could be a search for items that pertain to the volatility of a particular project, the uncertainty, and so on. In short, the VUCA meter is designed as a normative method to capture risk factors with VUCA semantics as a point of view [6]. This research aims to test whether 
the VUCA meter can improve the conventional risk identification process. It was done by selecting one large project currently under planning and testing the VUCA meter. Experts involved in the chosen project were divided into two workshops. Several focus questions were designed for each workshop. The purpose of the first workshop was to perform a risk identification and assessment based on the traditional framework presented in the PMI Standard for Risk Management in Portfolios, Programs, and Projects [8]. The purpose of the second workshop was to apply a new method for identifying and assessing risk based on the VUCA meter presented by Fridgeirsson and Ingason et al. [5]. The main focus of this study is to investigate whether the VUCA meter can supplement the conventional risk identification process by capturing Black Swan events in the domain of projects and project management. As the world is confronted with the enormous responsibilities related to, e.g., geopolitics, climate change, energy adaption, and social media, the isolation of risk that can harm sustainability seems imperative.

\section{Literature Review}

The importance of risk management in the context of project management has been widely discussed in the existing scientific literature $[14,15]$. All the tools and techniques used in risk management for projects are designed to help ensure that the project's delivered results are as expected and within identified constraints for the project. In the generic life cycle of projects, it is considered most effective when the risk events are identified and dealt with at an early stage of the project to be able to avoid big problems occurring in the project and to be aware of the risk events throughout its life cycle [7]. The risk management process is mainly divided into six steps: (1) Risk identification, where all possible risks that can have a negative impact on the project are identified; (2) risk assessment, including risk analysis, to determine which factors are the most important (riskiest) ones for the project; (3) a strategy and corresponding actions are developed and implemented to mitigate the risk; (4) monitoring and control of the risk; (5) report and integration against the risk; and (6) support for risk management, for example, with periodic project and risk meetings [16].

In this study, the emphasis is mainly on the beginning of the risk management process, the first two steps, where the risk events are identified and assessed. This is carried out using tools and techniques such as expert judgment, data gathering, data analysis, interpersonal and team skills, prompt lists, and meetings. Many of those involved in a project can contribute to the risk identification process, such as the project team members, customers, project manager, operations managers, stakeholders, end-users, and of course, the project risk specialist if assigned. Generally, the risk assessment is done by assessing on one hand the likelihood of a risk event occurring and on the other hand the impact of the same risk event on the project [17]. This conventional open approach to assess risk as described above has been disputed and there are several scientific research studies where it has been argued that this approach does not capture all the risk events that may affect the project, and significant risk events may be overlooked by using the conventional risk assessment techniques only $[5,9,13,18]$. That is because the likelihood of events to occur is one of the critical variables in the calculation when assessing the most significant risk events for the project. A case study from 2007 [9] discussed this systemic risk assessment. The authors argued that the most attention in the systemic risk assessment is devoted to the technical risk in projects, not other risk categories such as political risk, customer risk, partner and supplier risk, human risk, reputation risk, market, and financial risk.

In 2011, Geraldi, Maylor, and Williams published an article where they systematically reviewed the complexities of projects and pointed out that this is a key variable that impacts decisions in project management [19]. The type of complexity that is most frequently mentioned is structural complexity. Still, uncertainty is a relevant type of complexity and is one of the four concepts that constitute VUCA. The internal connection between complexity and risk was mentioned in the literature as early as in 1920 and has thus long been recognized [19]. In 2004, Linehan and Kavanagh defined projects as a confusing phenomenon that contain a lot of complexity and ambiguity, and the idea of a single clear 
goal is not realistic [20]. Still, even though complexity is such a challenging concept to study in project management, it is only one of the four concepts that VUCA consists of. Nancy Green provided a passable description of the characteristics of a risk event that might surpass the conventional risk assessment procedure based on the work of Nassim Taleb see Table 1 [21].

Table 1. The criteria for a Black Swan event adapted from [21].

\begin{tabular}{l}
\hline Emergency response to the problem and fixing the problem are different aspects. \\
\hline A solution to the problem is unknown and must be created under dismal circumstances. \\
Public relations issues can be massive, putting pressure on reputation, credibility, and perception \\
of the public. \\
Governmental and regulatory agencies may demand response. \\
Productivity and cash flow may be affected negatively, liquidity could become uncertain, and \\
asset prices disturbed. \\
Despite the problem, the day-to-day operation must continue.
\end{tabular}

Although VUCA is often named in connection with risk in the literature, a normative risk identification process based on VUCA is not. However, a noteworthy study on VUCA and risk assessment is Szpitter and Sadkowska who recommend using a VUCA matrix "to identify and analyze project risks, thus filling the research gap relating to the lack of application of this tool in analyses in the area of project risk management" [22]. Other notable studies on risk are $[23,24]$, connecting the VUCA era to supply sustainability management of supply chains.

The four components of VUCA are defined based on Bennett and Lemoine's [6] discussions and definition in their article from 2014. Bennett and Lemoine define each part carefully, as well as how to address them, and give clear examples to explain the semantics of VUCA. The semantics of the Bennet and Lemoine study on the characteristics of VUCA provided the authors with means to develop the sections of the VUCA risk identification meter. Each section of the meter must be addressed individually since they require a unique response. The VUCA meter used in this study is accessible in Appendix A to the article.

\section{The Case Study}

The case chosen for this research is a large public infrastructure project with a long planning and deployment horizon. The project is highly strategical as it is a part of an urban planning policy to increase the effectiveness of a transport system and contribute to environmental sustainability. The project has complicated stakeholder and shareholder structure that includes several municipalities and the government. The project requires large financial investments with a public-private partnership arrangement required for parts of the project. In the case of a huge cost overrun, the consequences would have a significant impact on the national economy.

\section{Methodology}

In the selection of participants for this study, a convenience sample was used. A convenience sample is a nonprobability or non-random sampling where the sample is gathered using predefined criteria, which means that not everyone has an equal chance to participate in the research [25]. When workshops are used as a research method, they are designed to fulfil the purpose of the study and used as a tool to collect data about a certain subject [25]. Workshops are today a well-established arrangement whereby a group of people learn, acquire new knowledge, perform creative problem-solving, or innovate in relation to a domain-specific issue [26]. Two workshops were lined up for the study. The main goal of the workshops was to apply and compare two different approaches for identification of risk factors in the selected project: firstly, a conventional risk identification as presented by PMI, where the main risk factors are identified on the basis on given 
focus questions and then rated on a scale for the likelihood of them occurring and the impact they would have; secondly, the VUCA risk identification method, where the main risk factors are identified based on five focus questions for each part of the term VUCA, 20 questions in total. In this case, the questions were composed based on the VUCA meter presented in the study by Fridgeirsson and Ingason et al. [5]. A group of ten experts working directly in the project preparation attended and were divided equally into two workshops. No one participated in both workshops and participants were instructed not to communicate regarding the workshops. The workshops were accurately planned and scheduled and were estimated to take around three hours each. Care was taken to make sure that the participants could prepare individually, so that the workshops would run as smoothly as possible. The questionnaire for the conventional risk identification was based on the traditional method presented in the PMI Standard for Risk Management in Portfolios, Programs, and Projects [8]. The questionnaire is divided into four focus questions and is answered by listing up factors that could be risky for the project related to each focus question. The focus questions are: (a) What risk events can impose operational risk? (b) What risk events can impose financial risk? (c) What risk events can impose legal and regulatory risk? and (d) What risk events can impose strategic risk?

In continuation, each risk factor is given value for the likelihood of occurring and for the impact, if it occurs. The values given for the likelihood and the impact are in the range of 1 to 5. The numbers indicate the following: (1) Very low, (2) Low, (3) Medium, (4) High, and (5) Very high.

The questionnaire developed for the VUCA risk identification is divided into four categories. Each category represents one of the four concepts VUCA consists of and each consist of five focus questions. These questions are as follows:

Volatility: (a) What complexity factors could lead to the need for many interfaces with other technologies, projects, or operations? (b) What volatility elements could lead to the need for more resources than expected? (c) What, from the perspective of volatility, could cause the project to take longer than planned? (d) What volatility factors could impact solid contract situation throughout the project timeline? (e) What volatility factors could cause the need for major changes in the objectives of the project?

Uncertainty: (a) What uncertainty factors could lead to the need for more information about technology components of the project? (b) What uncertainty factors could lead to the need for many stakeholders from different time zones? (c) What could cause the access to information to be limited due to uncertainty? (d) What uncertainty factors could impact well defined and approved scope? (e) What uncertainty factors could impact well-defined risk management?

Complexity: (a) What could lead to a complex political environment with many regulations to follow? (b) What complexity factors could lead to the need for many subcontractors, organizational departments, and cultural differences? (c) What complexity factors could lead to the need for many interfaces with other technologies, projects, or operations? (d) What are the factors of complexity making this a unique project not done before? (e) What complexity factors could make the decision-making not be straightforward?

Ambiguity: (a) What could cause the deliverables to not be as defined in the beginning due to ambiguity? (b) What ambiguity factors could cause the connections between tasks to become unclear? (c) What could lead to unexpected and unforeseen risk factors in an ambiguity environment? What could cause hidden agenda due to ambiguity? (e) What could lead to the need for unexpected/unknown stakeholders due to ambiguity? Brainstorming techniques were applied in both workshops and the individuals in the workgroups carefully facilitated. Pictures from the workshops can be found in Appendix B.

The data were analyzed in different ways, e.g., by using the multiplication rule of statistics to calculate the risk coefficient, the risk events were categorized, the range of the risk categories calculated, and even word clouds were prepared. However, these results are not the subject of the present study. The main objective of the study is to identify if the VUCA meter could identify "fat tail" risk events that would impact the 
project. The result section is therefore mainly reporting on the application of the beforedescribed characteristic of Black Swan events [21] to isolate such events from each of the two work groups.

Some risk factors were named in both workshops and therefore consequently removed from the list. The risk events identified in the respective workshops were then compared against the Black Swan criterions as defined by (E) in a two round Delphi technique survey using an adapted four-point Likert scale. The adaption involved removing the neutral option from the scale pressing the expert to decide the strength of the risk factor in context of the Black Swan attributes in Table 1. The expert panel consisted of students in the MPM (Master of Project Management) program at Reykjavik University. The MPM is a post graduate two-year course of studying project management. The MPM study line has been accredited by APM Association of Project Management and is approved by the Ministry of Education in Iceland. All students have training in project and risk management and experience from various industries. All students recognized the project under screening and were able to comprehend the complexities incurred. The expert panel contained 13 persons of both genders and an online tool was applied to conduct the Delphi two rounds.

\section{Results}

\subsection{Workshops}

The conventional method for risk identification delivered a total of 52 risk factors whereas 119 risk factors were obtained using the VUCA method, see Figure 1.

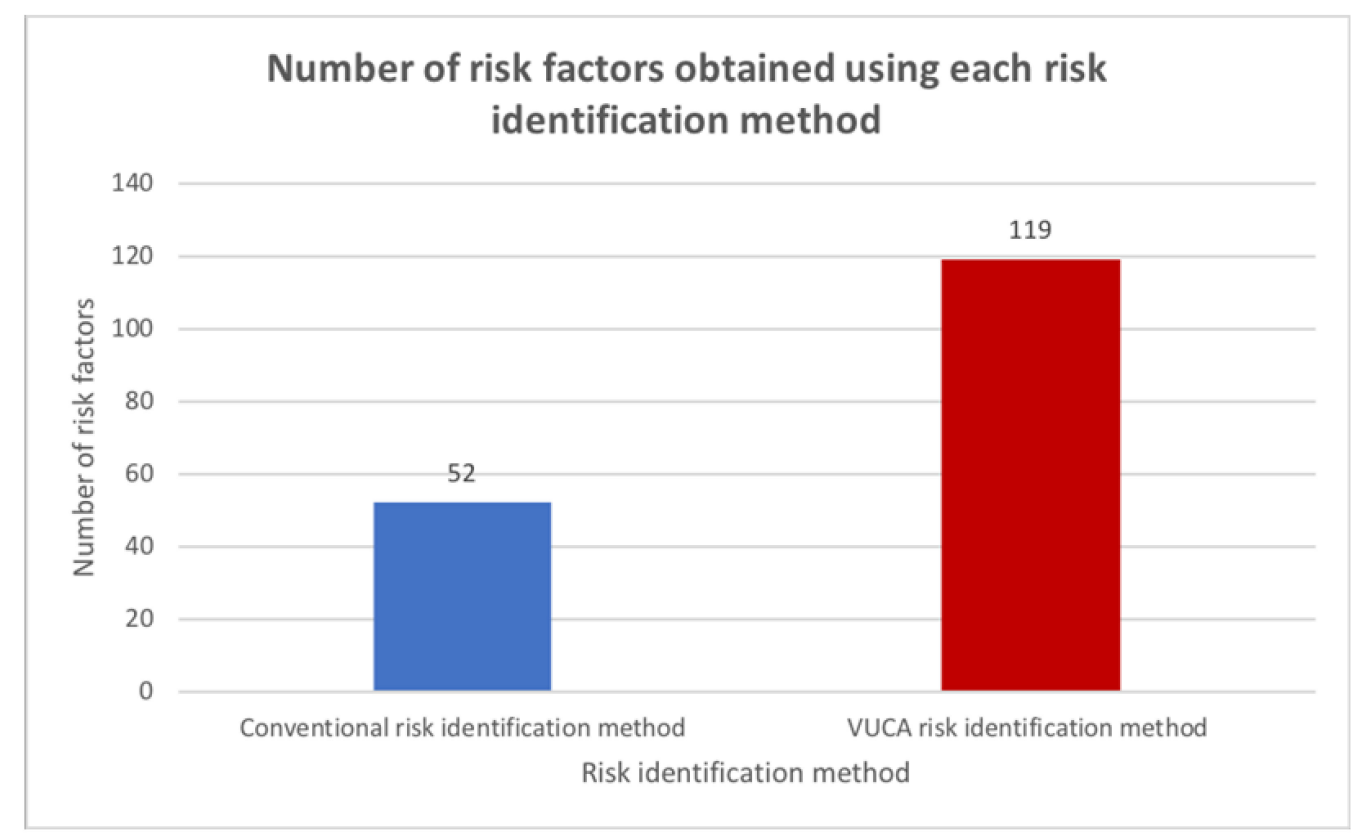

Figure 1. Number of risk factors obtained using each risk identification method.

A comparison of the risk factors obtained from each risk identification method shows that both methods captured risk factors that did not appear in the other method. The risk factors that only appeared when the traditional risk identification process was applied are shown in Table 2. The risk factors that were only captured by using the VUCA method are shown in Table 3. A large part of the risk factors identified were documented in both workshops, either in exactly the same form or with a different wording but the same meaning. 
Table 2. Risk factors only captured using the conventional risk identification method.

\begin{tabular}{l}
\hline Delays in other infrastructure (neighboring projects) \\
\hline Overheating in the construction market \\
\hline Failing to implement measures and incentives that will fulfil the project objectives \\
\hline Currency fluctuation \\
\hline Loss of reputation due to rights of construction personnel not followed \\
\hline The new infrastructure will not give enough priority for the vehicles \\
\hline Legal decision related to infrastructure, but operation is not catered for \\
\hline Complicated interaction between design, planning, and EIA \\
\hline The project not being able to bring expected urban qualities \\
\hline Difficulties in getting good placing for a depot \\
\hline Illegal size of fleet \\
\hline Failures in branding the project will not draw new users \\
\hline The project operation affected by delay in the system \\
\hline Uncertainties in volumes calculations \\
\hline Issues when obtaining land \\
\hline Problems with EIA laws
\end{tabular}

Table 3. Risk factors only captured using the VUCA risk identification method.

\begin{tabular}{l}
\hline Constantly needing reaffirming the ground/decision for the project \\
\hline No ultimate decision maker that can give final answer \\
\hline Decision on investment cost vs. maintenance cost (different budget) \\
\hline Some part of the projects is forgotten/not delivered \\
\hline The budget in manifesto will not be accepted every year by the government \\
\hline The sponsor pushing towards downscaling to achieve more for the same budget \\
\hline Change in key decision-makers \\
\hline Complexities due to the current setup/ownerships of the project \\
\hline Project scope is not clearly defined \\
\hline Relatively short construction period per phase \\
\hline Too much workload burns on the system \\
\hline Facts are not clear enough for decision making \\
\hline Uncertainty about who will run/operate part of the infrastructure \\
\hline Major disruption during construction-affecting the construction time \\
\hline Unexpected natural disasters, such as eruption, global warming, and climate \\
\hline Complexities due to neighboring large project 1 \\
\hline Complexities due to neighboring large project 2 \\
\hline Not clear what is included in the project-not clear project definition \\
\hline Ambiguity in toll discussion and policymaking \\
\hline Responsibilities are not clearly defined \\
\hline The municipalities pushing towards a larger scope-shifting the scope to manifesto \\
\hline Timelines for different part of the project are not clear \\
\hline
\end{tabular}


Table 3. Cont.

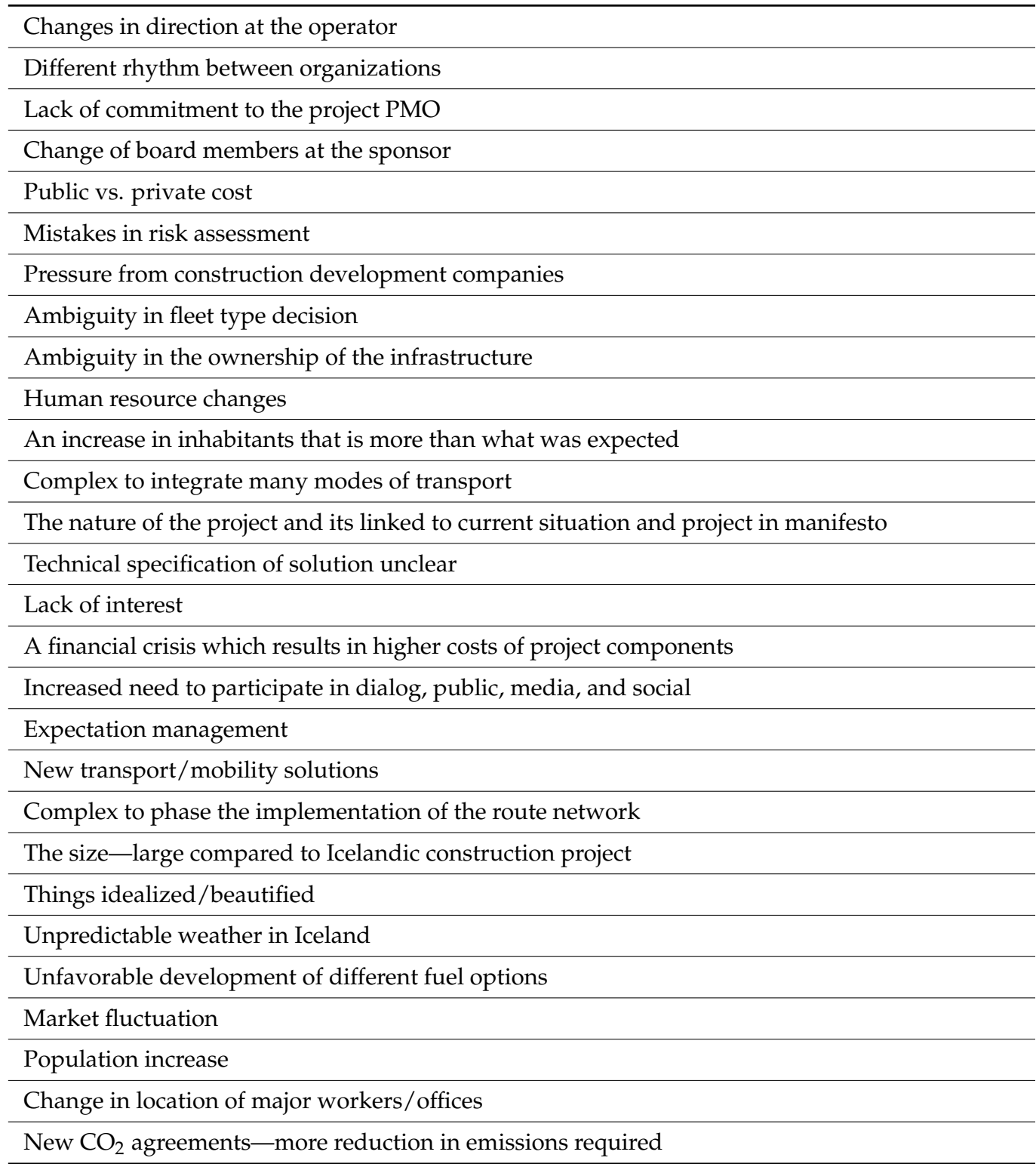

Another observation is worth mentioning. As mentioned in the literature review, Cirillo and Taleb [13] introduce the "tail risk" events as events that have much impact and shape our world, but are not likely to occur, and according to the authors are not as likely to be captured by using the conventional risk identification and assessment techniques. The risk factors having the lowest value for the likelihood of occurrence are all ranked in the range of 24 to 52 in the order of the risk coefficient obtained by the multiplication rule. The majority, or $70 \%$ of these risk factors, are ranked at 41 or later, which indicates that they are not considered very risky compared to the other risk factors. However, $60 \%$ of these risk factors have the value of impact in the range of 3.2 to 4 . By comparing these low probability factors to the riskiest factors obtained by using the VUCA method, it can be seen that $60 \%$ of these risk factors would have been among the ten riskiest events in the VUCA risk assessment, by only taking the impact into consideration. The participants in the workshops were asked to rate the impact for each risk factor on the scale of 1 to 5 . The participants in the workshop where conventional risk identification and assessment technique was used were also asked to rate the likelihood of occurrence for each risk factor. By getting this evaluation from the participants and viewing the average range in the answers from the participants from each workshop, it is possible to see the inconsistency 
in their evaluation of the risk factors. The results showed that there was much more inconsistency in the evaluating of risk factors obtained when the conventional method was used than when the VUCA method was used. The average range was 2.32 for the impact and 2.31 for the likelihood when the conventional method was used but 1.55 for the evaluation of the impact when the VUCA method was used.

The inconsistency in the answers can be traced to the measuring instruments which are in this case the people participating in the research. The people can look at the same things in different ways and the understanding can be different. That can be traced to that they may not have the exact same background and may be working for different segments of the project and therefore, they have different point of view when evaluating.

Lastly, it should be noted that many of the risk events that are products of the workshops are generic and it is not easy to interpret them for the analysts and, in this case, the authors. This obscurity occurred despite care taken in advance preparation of the participants prior to the workshops. This indicates the need to improve the risk assessment process, e.g., by educating the risk assessors of the importance of phrasing exactly the context of the risk.

\subsection{Delphi Surveys}

For the first round of the Delphi survey, a cut-off point of $>60 \%$ of the panelists either agreed or strongly agreed that the particular event is a Black Swan. The following list are the eight risk events from round no. 1 satisfying the $>60 \%$ criteria. As can be detected from Tables 2 and 3, two of those events appeared in the conventional risk workshop and six appeared in the VUCA workshop.

- $\quad$ Overheating in the construction industry creates problems

- Legal decision related to infrastructure taken, but operation is not catered for

- The sponsor pushing towards down-scaling to achieve more for the same budget

- Major disruption during construction-affecting the construction time

- Unexpected natural disasters, such as eruption, global warming, and climate

- Changes in direction at the operator

- A financial crisis which results in higher costs of project component

- Unfavorable development of different fuel options

The second round included only the eight risk factors above. The cut-off point of $>60 \%$ consensus among the panelists permitted the following risk factors as Black Swans.

- $\quad$ Overheating in the construction industry creates problems

- Major disruption during construction-affecting the construction time

- Unexpected natural disasters, such as eruption, global warming, and climate

- Changes in direction at the operator

- A financial crisis which results in higher costs of project component

One risk event is a product of the conventional workshop and four from the VUCA workshop.

\section{Discussion}

The study is based on preparing two kinds of risk identifications and assessments for the same project and executing this through two separate workshops with different sets of participants. We asked the question if the VUCA meter could augment the traditional risk identification practice by denoting risk events that may have been overlooked otherwise. The results are interesting and indicate that the assumption is valid. The findings can give an idea of the usefulness of the VUCA meter in terms of project risk identification.

By comparing the results from the VUCA risk identification method and the conventional risk identification method, it is evident that the number of risk factors identified by each method were different. The number of risk factors obtained by using the conventional method was 51 compared to 119 risk factors when using the VUCA method. This is a huge difference given that the time for both workshops was identical. The only difference 
between the workshops was the work process; the approach that was used to elicit answers from the participants.

The conventional probabilistic and event-based approaches to risk assessment are great and have proven their usefulness. They do, however, have their limitations, especially when it comes to unpreceded events involving low-probability/high-impact risks, system risks, and risks that are less technical and more psychological/social in nature. Noteworthy is the study by Ackermann et al., who presented the "risk filter" that uses insights from forensics to identify risk exposure on future projects and tackle them [9]. Another study stating the difficulties of the conventional approach is by Qin et al. [27]. Titko et al. did an interesting study on how the escalation and severity of natural disasters will affect the public and need for new ways to approach the incurred risks [28]. Lastly, the authors would like to mention the cognitive theories of Amos Tversky and Daniel Kahneman on human limitations of decision making, see, e.g., [10,29]. The conventional method is an open approach relying on the experience and the cognitive state of mind of the participants. The VUCA meter is a normative approach that asks questions in a certain context. For the conventional workshops, five questions related to the conventional topics of a risk identification process were used to elicit risk factors, one at a time. In the VUCA workshops, 20 focus questions were used to elicit risk factors, five questions for each component part of VUCA. In this case, five focus questions were answered at a time. The results indicate that the VUCA method might be a better way to force people to think somewhat beyond the traditional framework used for identifying risk factors in a project. The traditional framework included operational, financial, legal and regulatory, and strategic risk, but projects in modern times are faced with risk that is not necessarily encapsulated by this framework. Furthermore, the VUCA method may help to bypass cognitive biases that are well known sources for risk, see, e.g., the landmark studies of Daniel Kahneman and Amos Tversky [10]. The risk factors that were captured using the VUCA method but not with the conventional method were of different kinds. Still, most of them seem to be related to the social and the environmental part of the project. This is the outcome of a framework that directed the participants to think of risk factors that occur as a result of the time of volatility, uncertainty, complexity, and ambiguity.

\section{Conclusions}

The authors have confidence in that the VUCA meter can be developed further and provide risk managers with a valuable tool to capture risk factors that would be undetected by a conventional method. It could also be interesting to take this research further. Future studies should select more than one project from different sectors in order to assess if this VUCA method works differently in different sectors. Subsequently, it would be interesting to develop a method which is a combination of the two methods and try this new method to identify and assess potential risk factors for projects. The outcome will be some kind of improved version of the existing conventional method currently in place to identify and assess project risk. Lastly, a study based on the present study with improved VUCA semantics and an improved process to ensure a clear context of the risk events is likely to provide even better results. It is also worth mentioning that the authors have now, in light of the results and observations of this study, issued a new version of the VUCA meter. The new version comes with more comprehensive semantics and vocabulary. Moreover, an exact template on the work procedure has been devised. This is a process leading the facilitator and the team of analyst in steps toward a solution.

Author Contributions: T.V.F. led the study and arranged the paper in the present conceptualization form. He also supervised the research, designed the Delphi surveys, and facilitated the workshops. H.T.I. supervised the research and contributed to the management of the workshops, surveys, and writing. A.Y.G. was the main researcher in the initial investigation and contributed to writing. S.H.B. contributed to writing, review, and editing. All authors have read and agreed to the published version of the manuscript. 
Funding: This research received no external funding.

Institutional Review Board Statement: The study was conducted according to the guidelines of the Declaration of Helsinki and approved in accordance with the requirements of the Institutional Review Department of Reykjavik University (RU-MPM-Review-Board-May 2020, 1 May 2019).

Informed Consent Statement: Informed consent was obtained from all subjects involved in the study.

Data Availability Statement: Not applicable.

Conflicts of Interest: Authors declare that no conflict of interest is connected to this study.

\section{Appendix A. The VUCA Meter}

\begin{tabular}{|c|c|c|c|c|c|c|c|}
\hline Criteria & \multicolumn{5}{|c|}{ Compliance Weights } & \multirow{2}{*}{$\begin{array}{l}\text { Avg. } \\
\text { Score }\end{array}$} & \multirow{2}{*}{$\begin{array}{c}\text { Statement } \\
\text { Score } \\
\text { Range } \\
\end{array}$} \\
\hline Volatility & 1 & 2 & 3 & 4 & 5 & & \\
\hline \multicolumn{8}{|c|}{$\begin{array}{l}\text { Simple in planning (straightforward/sequential } \\
\text { execution) }\end{array}$} \\
\hline \multicolumn{8}{|c|}{ Resource needs are known and accessible } \\
\hline \multicolumn{8}{|c|}{ Adequate timeframe with good slack in schedule } \\
\hline \multicolumn{8}{|c|}{ Solid contracts throughout project duration } \\
\hline \multicolumn{8}{|l|}{ Known, well defined objectives } \\
\hline \multicolumn{8}{|c|}{ Average score: } \\
\hline \multicolumn{8}{|c|}{ Project score range: } \\
\hline Uncertainty & 1 & 2 & 3 & 4 & 5 & & \\
\hline \multicolumn{8}{|c|}{ Uses few and proven technology components } \\
\hline \multicolumn{8}{|l|}{$\begin{array}{l}\text { Stakeholders are few, with few time } \\
\text { zones/cultural differences }\end{array}$} \\
\hline \multicolumn{8}{|l|}{ Information is easy to obtain } \\
\hline \multicolumn{8}{|l|}{ Scope is well defined and approved } \\
\hline \multicolumn{8}{|l|}{ Risk management is well defined } \\
\hline \multicolumn{8}{|c|}{ Average score: } \\
\hline \multicolumn{8}{|c|}{ Project score range: } \\
\hline Complexity & 1 & 2 & 3 & 4 & 5 & & \\
\hline \multicolumn{8}{|l|}{$\begin{array}{l}\text { Few and simple regulatory or political } \\
\text { environments }\end{array}$} \\
\hline \multicolumn{8}{|c|}{$\begin{array}{l}\text { Few subcontractors, organizational departments, } \\
\text { and cultural differences }\end{array}$} \\
\hline \multicolumn{8}{|c|}{$\begin{array}{l}\text { Few interfaces with other technologies, projects or } \\
\text { operations }\end{array}$} \\
\hline \multicolumn{8}{|l|}{ Has been done many times before } \\
\hline \multicolumn{8}{|l|}{$\begin{array}{l}\text { Clear governance, straightforward } \\
\text { decision-making }\end{array}$} \\
\hline \multicolumn{8}{|c|}{ Average score: } \\
\hline \multicolumn{8}{|c|}{ Project score range: } \\
\hline Ambiguity & 1 & 2 & 3 & 4 & 5 & & \\
\hline \multicolumn{8}{|c|}{$\begin{array}{l}\text { Deliverables are well defined, no "unknowns } \\
\text { unknowns" }\end{array}$} \\
\hline Connections between tasks are clear & & & & & & & \\
\hline
\end{tabular}




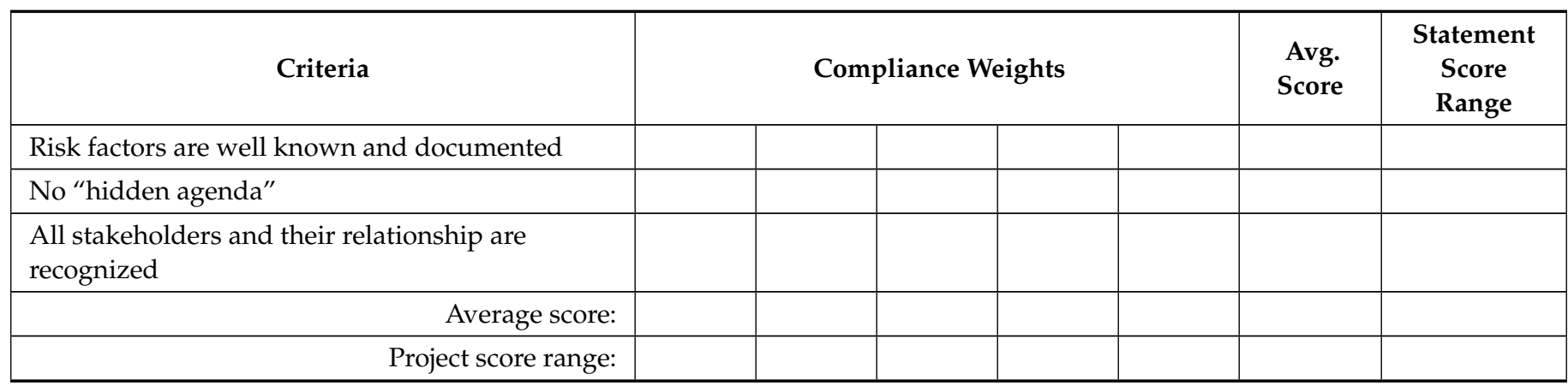

\section{Appendix B. Pictures from the Workshops}

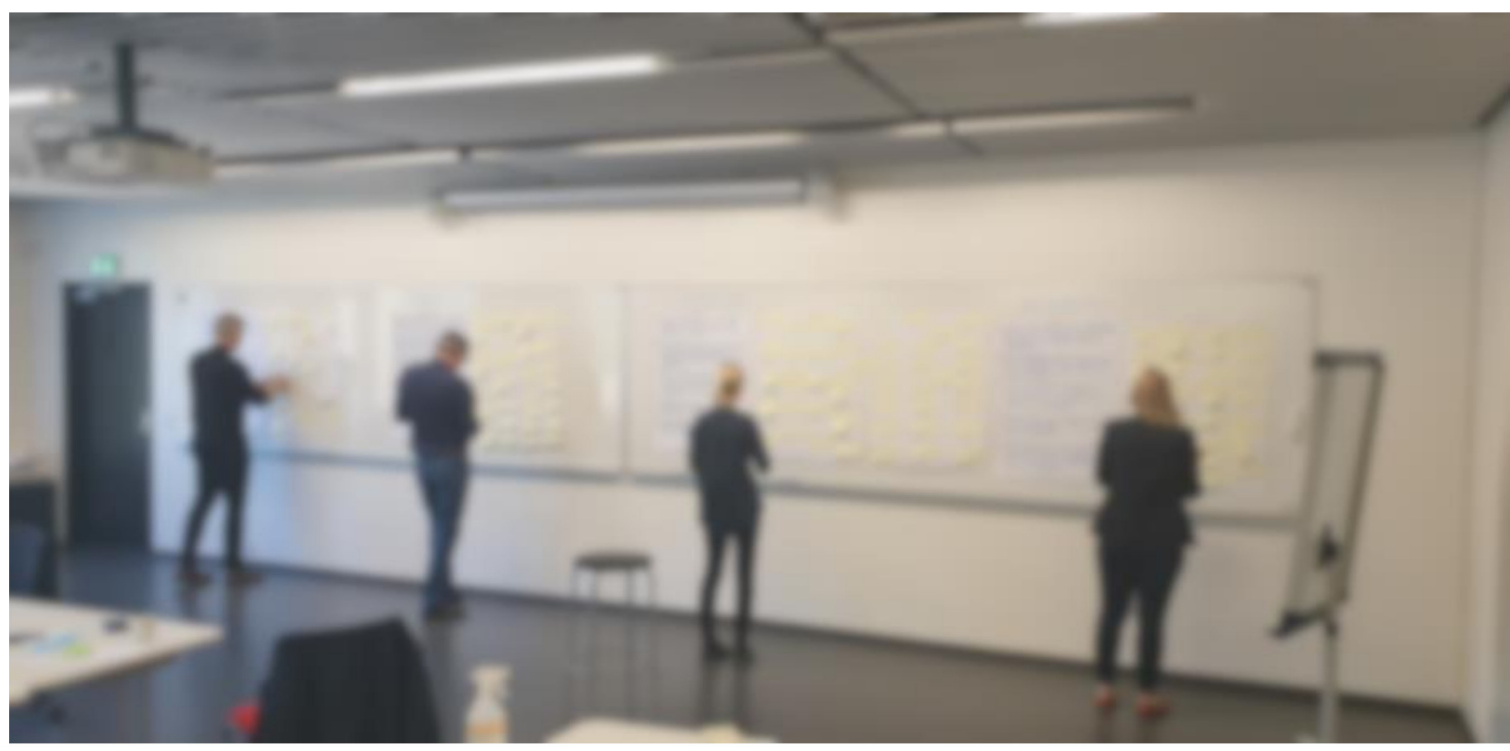

Figure A1. The conventional risk identification workshop. Photo taken on site by the authors.

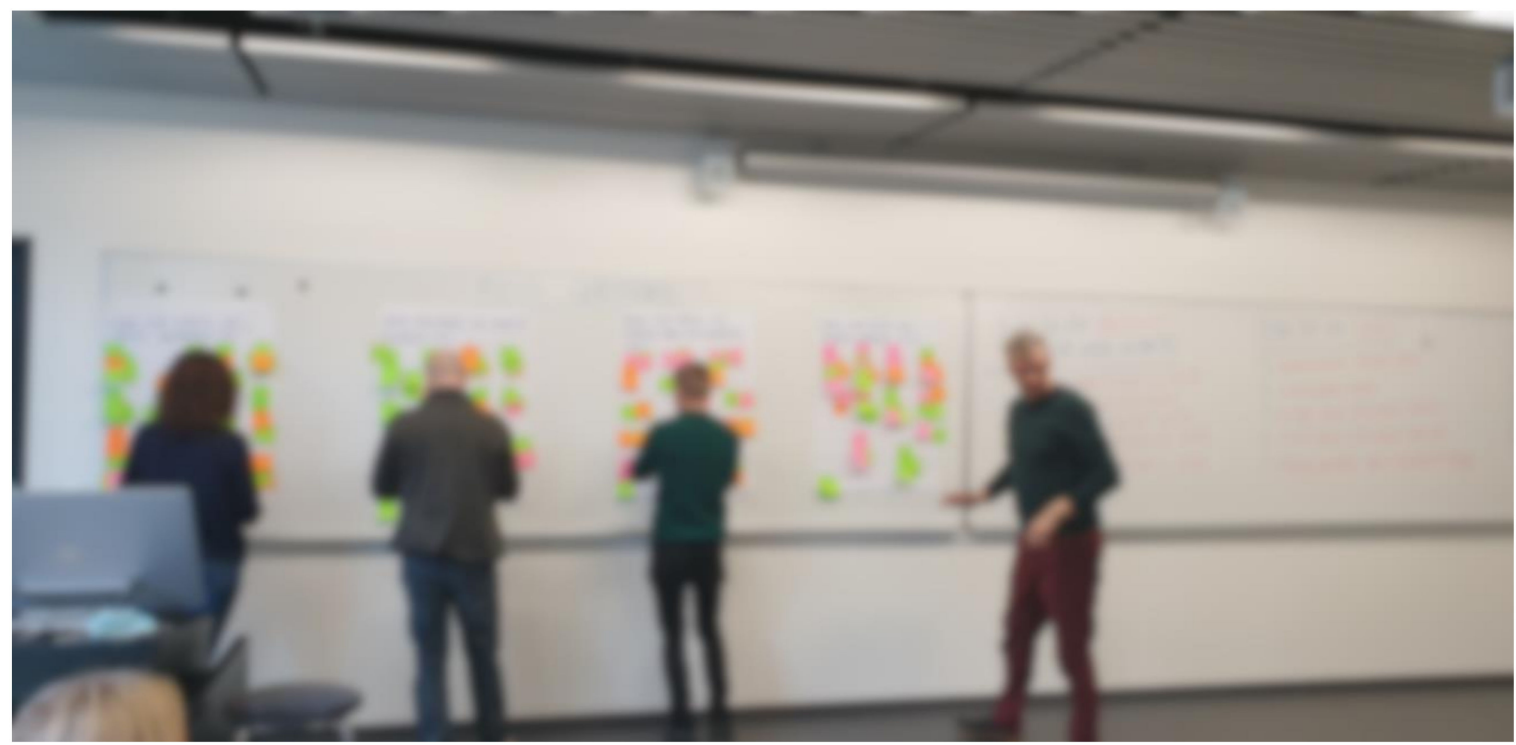

Figure A2. The VUCA risk identification workshops. Photo taken on site by the authors. 


\section{References}

1. Vaðlaheiðarganga, Saga. Available online: https://www.vadlaheidi.is/is/sagan (accessed on 18 October 2021).

2. Heidarson, J.T. Vaðlaheiðargöng-Mat á Pjóðhagslegri Arðsemi, January 2006. Available online: https://www.rha.is/static/ files/Rannsoknir/2006/Skyrsla_loka.pdf (accessed on 18 October 2021).

3. Kjarninn. Available online: https:/ / kjarninn.is/frettir/2018-03-12-let-reikna-kostnad-vid-vadlaheidargong-i-samraemi-vidlog-um-rikisabyrgdir/ (accessed on 18 October 2021).

4. DV. Available online: https://www.dv.is/frettir/2019/07/15/tekjur-vadlaheidarganga-65-70-minni-en-aaetlad-var (accessed on 18 October 2021).

5. Fridgeirsson, T.; Ingason, H.; Jonasson, H.; Kristjansdottir, B. The VUCAlity of Projects: A New Approach to Assess a Project Risk in a Complex World. Sustainability 2021, 13, 3808. [CrossRef]

6. Bennett, N.; Lemoine, G.J. What a difference a word makes: Understanding threats to performance in a VUCA world. Bus. Horiz. 2014, 57, 311-317. [CrossRef]

7. Thamhain, H. Managing Risks in Complex Projects. Proj. Manag. J. 2013, 44, 20-35. [CrossRef]

8. PMI. Project Management Institute, The Standard for Risk Management in Portfolios, Programs, and Projects; PMI: Newtown Square, PA, USA, 2019.

9. Ackermann, F.; Eden, C.; Williams, T.; Howick, S. Systemic risk assessment: A case study. J. Oper. Res. Soc. 2007, 58, 39-51. [CrossRef]

10. Kahneman, D.; Tversky, A. Prospect Theory: An Analysis of Decision under Risk. Econometrica 1979, 47, 263-291. [CrossRef]

11. Flyvbjerg, B.; Glenting, C.; Rønnest, A. Procedures for Dealing with Optimism Bias in Transport Planning; The British Department for Transport, Guidance Document: London, UK, 2004.

12. The Black Swan: The Impact of the Highly Improbable: With a New Section: "On Robustness and Fragility" (Incerto) Paperback-11 May, 2nd ed.; Random House Publishing Group: New York, NY, USA, 2007.

13. Cirillo, P.; Taleb, N.N. Tail risk of contagious diseases. Nat. Phys. 2020, 16, 606-613. [CrossRef]

14. Ward, S.C.; Chapman, C.B. Risk-management perspective on the project lifecycle. Int. J. Proj. Manag. 1995, 13, 145-149. [CrossRef]

15. Morris, P.W.G.; Pinto, J.; Söderlund, J. Introduction: Towards the Third Wave of Project Management; Oxford University Press: Oxford, UK, 2011.

16. Rodrigues-Da-Silva, L.H.; Crispim, J. The Project Risk Management Process, a Preliminary Study. Procedia Technol. 2014, 16, 943-949. [CrossRef]

17. PMI. Foundational Standards; PMI: Newtown Square, PA, USA, 2017.

18. Nieto-Morote, A.; Ruz-Vila, F. A fuzzy approach to construction project risk assessment. Int. J. Proj. Manag. 2011, 29, $220-231$. [CrossRef]

19. Geraldi, J.; Maylor, H.; Williams, T. Now, let's make it really complex (complicated). Int. J. Oper. Prod. Manag. 2011, 31, 966-990. [CrossRef]

20. Linehan, C.; Kavanagh, D. From Project Ontologies to Communities of Virtue; Department of Management \& Marketing University College Cork, National University of Ireland: Cork, Ireland, 2004.

21. Green, N. Keys to Success in Managing a Black Swan Event [White Paper], AON Corporation. Available online: http://www.aon. com/attachments/risk-services/Manage_Black_Swan_Even_Whitepaper_31811.pdf (accessed on 9 October 2021).

22. Szpitter, A.; Sadkowska, J. Using VUCA matrix for the assessment of project environment risk. Zarzadzanie Finans. 2016, $14,401-413$.

23. Ocicka, B.; Jolanta, T. "Supply Chain Sustainability Risk Management in a Digitally VUCA Changing World". In The Economics of Sustainable Transformation; Routledge: New York, NY, USA, 2021; pp. 167-190.

24. Gao, Y.; Feng, Z.; Zhang, S. Managing supply chain resilience in the era of VUCA. Front. Eng. Manag. 2021, 8, 465-470. [CrossRef]

25. Etikan, I.; Musa, S.A.; Alkassim, R.S. Comparison of Convenience Sampling and Purposive Sampling. Am. J. Theor. Appl. Stat. 2016, 5, 1-4. [CrossRef]

26. Ørngreen, R.; Levinsen, K. “Workshops as a Research Methodology". Electron. J. E-Learn. 2017, 15, 70-81.

27. Qin, J.; Xi, Y.; Witold, P. Failure mode and effects analysis (FMEA) for risk assessment based on interval type-2 fuzzy evidential reasoning meth-od. Appl. Soft Comput. 2020, 89, 106134. [CrossRef]

28. Titko, M.; Ristvej, J.; Zamiar, Z. Population preparedness for disasters and extreme weather events as a predictor of building a resilient society: The Slovak Republic. Int. J. Environ. Res. Public Health 2021, 18, 2311. [CrossRef] [PubMed]

29. Kahneman, D. Thinking, Fast and Slow; Macmillan: New York, NY, USA, 2011. 